\title{
Descriptive Study on Skin Prick Test in Allergy Clinic Immanuel Hospital Bandung Indonesia
}

\author{
Danny R. Garna*, Johan Lucianus**, July Ivone*** \\ *Faculty of Medicine Maranatha Christian University \\ **Microbiology Department Faculty of Medicine Maranatha Christian University \\ *** Public Health Department Faculty of Medicine \\ Maranatha Christian University \\ Jl. Prof. Drg. Suria Sumantri MPH No. 65 Bandung 40164 Indonesia \\ Email: danny.garna@gmail.com
}

\begin{abstract}
Allergy is a change of reaction or body's defense response to substances that are actually harmless. An estimated 10-20\% of the population had been or are suffering from the disease. The purpose of this study was to thoroughly observe allergic patients on Allergy Clinic Immanuel Hospital Bandung from January 2013-January 2014 based on allergen, clinical sign, age and gender. This study use descriptive methods with retrospective data retrieval from medical record. We gathered 206 skin prick test (SPT) results and found that the highest incidence of allergy was between 31-40 years (22.33\%), 64.54\% were women, $43.20 \%$ of patients with dermatitis as the major clinical signs, $70.59 \%$ of patients allergic to house dust mite as a common environmental allergens, $24.84 \%$ of patients allergic to shrimp as the most common food allergens. In conlusion, allergic patients with SPT positive common at the age of 31-40 years, women, Dermatitis as a major clinical signs. The most common environmental allergens that cause allergy was house dust mite. The most common food allergens that cause allergy was shrimp.
\end{abstract}

Keywords: allergy, dermatitis, Immanuel Hospital Bandung, skin prick test 


\title{
Penelitian Deskriptif pada Pasien Alergi di Klinik Alergi Rumah Sakit Immanuel Bandung Indonesia
}

\author{
Danny R. Garna*, Johan Lucianus ${ }^{* *}$, July Ivone ${ }^{* * *}$ \\ *Fakultas Kedokteran Universitas Kristen Maranatha \\ **Bagian Mikrobiologi Fakultas Kedokteran Universitas Kristen Maranatha \\ ***Bagian Ilmu Kesehatan Masyarakat Fakultas Kedokteran Universitas Kristen \\ Maranatha \\ J1. Prof. Drg. Suria Sumantri MPH No. 65 Bandung 40164 Indonesia \\ Email: danny.garna@gmail.com
}

\begin{abstract}
Abstrak
Alergi adalah suatu perubahan reaksi atau respons pertahanan tubuh terhadap zat-zat yang sebenarnya tidak berbahaya. Diperkirakan 10-20\% penduduk pernah atau sedang menderita penyakit tersebut. Penelitian ini bertujuan untuk mengetahui gambaran pasien alergi di Klinik Alergi Rumah Sakit Immanuel periode Januari 2013 - Desember 2014 berdasarkan penyebab alergi, tanda klinis, usia, dan jenis kelamin Penelitian ini bersifat deskriptif dengan pengambilan data secara retrospektif dari data rekam medik pasien alergi.Terdapat 206 pemeriksaan skin prick test (SPT) pada pasien alergi dengan insidensi tersering pada kelompok usia 31-40 tahun $(22,33 \%), 64,54 \%$ adalah perempuan, $43,20 \%$ pasien dermatitis sebagai tanda klinik tersering, 70,59\% pasien alergi terhadap tungau debu rumah (TDR) sebagai alergen lingkungan tersering, 24,84\% pasien alergi terhadap udang sebagai alergen makanan tersering, Dapat disimpulkan alergi dengan SPT positif tersering didapatkan pada usia 31-40 tahun, perempuan, dan dermatitis merupakan tanda klinik utama. Alergen lingkungan tersering yang menyebabkan alergi adalah tungau debu rumah. Alergen makanan tersering yang menyebabkan alergi adalah udang.
\end{abstract}

Kata kunci: alergi, dermatitis, Klinik Alergi Rumah Sakit Immanuel, skin prick test 
Research Article

\section{Pendahuluan}

Penyakit alergi merupakan kumpulan penyakit yang sering dijumpai di masyarakat. Diperkirakan 10-20\% penduduk pernah atau sedang menderita penyakit tersebut. Alergi sering mengenai organ saluran napas, kulit, dan saluran pencernaan. ${ }^{1}$ Pemeriksaan double-blind, placebo-controlled food challenge (DBPCFC) dianggap sebagai gold standard pemeriksaan alergi, namun waktu yang dihabiskan, penggunaan bahan, dan kemungkinan terjadinya anafilaksis membuat dibutuhkan pemeriksaan yang lebih aman dan murah. Pemeriksaan In vivo seperti skin prick test (SPT) dan immunoglobulin E (IgE) spesifik adalah pemeriksaan lini pertama untuk menilai sensitasi IgE. ${ }^{2}$

Tes kulit sebagai sarana penunjang diagnosis penyakit alergi, telah dilakukan sejak lebih dari 100 tahun yang lalu, karena sederhana dan terbukti memiliki hasil positif yang sama dengan kadar IgE spesifik atau tes provokasi. Tes kulit terbagi menjadi: skin prick test, scracth test, friction test, patch test, dan intradermal test. Di antara berbagai tes ini yang paling sering digunakan adalah skin prick test karena mudah, murah, spesifik, dan aman. Menurut laporan yang ada di Indonesia, skin prick test ini hampir tidak pernah menimbulkan efek samping. ${ }^{2}$

Makanan merupakan salah satu penyebab reaksi alergi. Walaupun kejadian alergi makanan lebih sering ditemui pada anak-anak, penelitian terbaru melaporkan 1,4 - 6\% populasi dewasa pernah mengalami alergi makanan. Prevalensi pada perempuan dewasa dilaporkan lebih banyak daripada laki-laki dewasa. Sebagian besar alergi makanan sudah muncul pada masa kanak-kanak. ${ }^{3}$

Kejadian alergi makanan di Klinik Alergi Rumah Sakit Immanuel selama periode Januari 2006 sampai dengan Desember 2006 sebanyak 197 orang. Dimana makanan yang sering menyebabkan alergi adalah kepiting (47,71\%), susu sapi (42,64\%), dan ikan bandeng (40,10\%). Manifestasi klinik terbanyak adalah dermatitis sebanyak 63 orang $(31,98){ }^{4}$

Samsuridjal dkk. melaporkan penyakit alergi yang tersering dijumpai di Bagian Penyakit Dalam RSCM Jakarta adalah asma, rhinitis, urtikaria, dan alergi makanan. Di Medan, Tanjung A melaporkan insidensi tanda klinis terbanyak pasien alergi saluran napas merupakan rhinitis kronis $(41,9 \%)$, asma $(30,6 \%)$ dan rhinitis akut (25\%), serta batuk kronis (5\%). ${ }^{1}$

Klinik Alergi Rumah Sakit Immanuel menerima rujukan pasien departemen lain yang mengalami gejala alergi atau dicurigai mengalami alergi. Pada Klinik Alergi dilakukan pemeriksaan penunjang dan juga penatalaksanaan. Tujuan dari penelitian ini adalah untuk mengetahui gambaran pasien alergi di Rumah Sakit Immanuel berupa gambaran usia, jenis kelamin, tanda klinis, dan penyebab tersering yang dijumpai. 
Research Article

\section{Metode}

Metode penelitian yang digunakan adalah metode deskriptif dengan pengambilan data secara retrospektif dari data rekam medik pasien alergi di Klinik Alergi Rumah Sakit Immanuel periode Januari 2013 - Desember 2014 dengan teknik pengambilan data secara whole sampling.

\section{Hasil}

Insidensi alergi terbanyak didapatkan pada usia 31- 40 tahun sebanyak 46 orang $(22,33 \%)$ sebagaimana tercantum pada tabel 1 . Pada penelitian lain yang dilakukan di RSUD Dr. Soetomo Surabaya periode 2007-2012 didapatkan kelompok usia 25-44 tahun sebagai kelompok penderita dermatitis atopi tersering. ${ }^{5}$

Tabel 1 Usia Pasien Alergi yang Dilakukan Pemeriksaan SPT di Klinik Alergi Rumah Sakit Immanuel periode Januari 2013 - Desember 2014

\begin{tabular}{ccc}
\hline Usia & $\underline{\text { Jumlah }}$ & Persentase $(\%)$ \\
\hline 0-10 tahun & 22 & 10,68 \\
11-20 tahun & 36 & 17,47 \\
21-30 tahun & 40 & 19,42 \\
$31-40$ tahun & 46 & 22,33 \\
41-50 tahun & 32 & 15,53 \\
$51-60$ tahun & 20 & 9,71 \\
61-70 tahun & 7 & 3,40 \\
Tidak ada data & 3 & 1,46 \\
\hline Total & 206 & 100 \\
\hline
\end{tabular}

Dari data hasil penelitian didapatkan penderita perempuan sebanyak 133 orang $(64,54 \%)$, lebih banyak daripada penderita laki-laki sebanyak 71 orang $(34,47 \%)$ (Tabel 2). 
Tabel 2 Jenis Kelamin Pasien Alergi yang Dilakukan Pemeriksaan SPT di Klinik Alergi Rumah Sakit Immanuel Periode Januari 2013 - Desember 2014

\begin{tabular}{ccc}
\hline Jenis Kelamin & Jumlah & Persentase (\%) \\
\hline Laki - Laki & 71 & 34,47 \\
Perempuan & 133 & 64,54 \\
Tidak ada data & 2 & 0,97 \\
\hline Total & 206 & 100 \\
\hline
\end{tabular}

Tanda klinis alergi dapat dijumpai pada kulit, saluran nafas dan saluran cerna ${ }^{3}$. Tanda klinis pasien yang dilakukan pemeriksaan SPT di Klinik Alergi Rumah Sakit Immanuel periode Januari 2013 - Desember 2014 dapat dilihat pada tabel 3.

Tabel 3 Tanda Klinis Pasien Alergi dengan Pemeriksaan SPT di Klinik Alergi Rumah Sakit Immanuel Periode Januari 2013 - Desember 2014

\begin{tabular}{ccc}
\hline Tanda Klinis & Jumlah & Persentase (\%) \\
\hline Dermatitis & 89 & 43,20 \\
Urtikaria & 80 & 38,83 \\
Rinitis & 16 & 7,76 \\
Prurigo & 5 & 2,43 \\
Asma & 2 & 0,97 \\
Bronchitis Alergi & 3 & 1,46 \\
Lain-Lain & 11 & 5,37 \\
\hline Total & 206 & 100
\end{tabular}

Pada hasil penelitian uji SPT yang dilakukan di Klinik Alergi Rumah Sakit Immanuel periode Januari 2013 - Desember 2014 menggunakan 18 jenis bahan uji SPT dengan alergen lingkungan yang diujikan sebanyak 8 jenis allergen, yaitu TDR, nyamuk, kecoa, bulu anjing, bulu kucing, jamur Candida sp, latex dan rumput. Pada hasil penelitian didapatkan insidensi alergen lingkungan tertinggi adalah TDR, sebagai penyebab alergi tersering, yaitu sebanyak 108 orang $(70,59 \%)$ (Tabel 4). 
Tabel 4 Jumlah Kasus Berdasarkan Penyebab Alergen Lingkungan di Klinik Alergi Rumah Sakit Immanuel Periode Januari 2013 - Desember 2014

\begin{tabular}{ccc}
\hline Jenis Penyebab & Jumlah & Persentase \% \\
\hline Tungau Debu Rumah & 108 & 70,59 \\
Nyamuk & 71 & 46.41 \\
Kecoa & 67 & 43,79 \\
Bulu Anjing & 25 & 16,34 \\
Bulu Kucing & 18 & 11,76 \\
Jamur Candida sp. & 17 & 11,11 \\
Latex & 9 & 5,88 \\
Rumput & 7 & 4,58 \\
\hline
\end{tabular}

Pada hasil penelitian uji SPT yang dilakukan di Klinik Alergi Rumah Sakit Immanuel periode Januari 2013 - Desember 2014 dilakukan pemeriksaan terhadap 10 jenis makanan. Pada hasil penelitian dari 166 orang subjek penelitian, berdasarkan jenis alergen makanan didapatkan insidensi tertinggi adalah udang $(24,84 \%)$ (Tabel 5)

Tabel 5 Jumlah Kasus Berdasarkan Penyebab Alergen Makanan di Klinik Alergi Rumah Sakit Immanuel Periode Januari 2013 - Desember 2014

\begin{tabular}{ccc}
\hline Jenis Penyebab & Jumlah & Persentase (\%) \\
\hline Udang & 38 & 24,84 \\
Kacang Tanah & 18 & 11,76 \\
Soya / Kedelai & 17 & 11,11 \\
Kepiting & 15 & 9,80 \\
Wortel & 13 & 8,50 \\
Ikan Tuna & 11 & 7,83 \\
Pisang & 11 & $7, .19$ \\
Ayam & 6 & 3,92 \\
Sereal Mix & 6 & 3,92 \\
Telur Ayam & 4 & 3,01 \\
\hline
\end{tabular}

\section{Diskusi}

Dari penelitian yang dilakukan di RS Cipto Mangunkusumo pada tahun 2007 didapatkan hasil pasien dewasa dibandingkan anak-anak lebih banyak sensitif terhadap alergi makanan. ${ }^{6}$ Di Amerika Serikat penderita alergi terbanyak adalah usia 35-64 tahun. ${ }^{7}$ Hal ini disebabkan karena paparan berulang dapat memicu timbulnya alergi pada seseorang, maka semakin bertambah usia seseorang, kemungkinan terpapar alergi semakin meningkat. ${ }^{8}$ Kejadian alergi juga dipengaruhi oleh faktor fisik seperti kelelahan dan aktivitas berlebih, faktor emosi seperti kecemasan, sedih, stres atau ketakutan maupun faktor hormonal juga memicu alergi pada orang dewasa. ${ }^{9}$ Hasil negatif pada penelitian ini tidak menandakan bahwa pasien tidak memiliki 


\section{Research Article}

alergi sama sekali namun menunjukkan fakta bahwa pasien tidak memiliki alergi terhadap jenis alergen yang diujikan pada penelitian ini.

Jenis kelamin tersering ditemukan pada perempuan sesuai dengan penelitian SPT pada RSUP Prof. DR.R.D. Kandou Manado pada periode Januari 2010- Oktober 2012, yang menunjukkan bahwa dari 119 orang subjek penelitian dengan SPT alergi terhadap tungau debu rumah positif, didapatkan hasil perempuan memiliki insidensi alergi lebih tinggi dibanding lakilaki. ${ }^{10}$ Hal serupa juga ditemukan di RS Cipto Mangunkusumo pada tahun 2007 dengan angka kejadian alergi pada perempuan lebih tinggi dibandingkan pada laki laki. ${ }^{6}$ Hal yang sama ditemukan pada mahasiswa dengan gejala rhinitis alergi pada Fakultas Kedokteran Universitas Riau dimana 37 dari 49 subjek penelitian SPT adalah wanita. ${ }^{11}$ Pada RSUD Dr. Soetomo Surabaya Periode 2007-2012 didapatkan persentase jenis kelamin yang menderita alergi lebih banyak pada perempuan. ${ }^{5}$ Tidak ada perbedaan reaksi skin prick test terhadap perbedaan jenis kelamin. Hubungan antara angka kejadian alergi dengan jenis kelamin sendiri belum diketahui secara pasti. ${ }^{12}$

Hasil penelitian data yang diperoleh pada pemeriksaan alergi makanan dan lingkungan pada periode Januari 2013 - Desember 2014 ini, tanda klinis yang paling sering ditemui adalah dermatitis sebanyak 89 orang $(43,20 \%)$. Berdasarkan sistem tanda klinisnya, penderita alergi yang menimbulkan tanda klinis pada kulit sebanyak 179 orang $(86,41 \%)$ dan pada saluran nafas 21 orang $(10,19 \%)$. Penelitian yang dilakukan untuk alergi makanan yang sebelumnya dilakukan di Klinik Alergi Rumah Sakit Immanuel periode April 2002 sampai dengan Maret 2003, tanda klinis alergi makanan yang paling sering ditemukan adalah dermatitis sebanyak 43 orang $(33,07 \%) .{ }^{13}$ Hal yang sama ditemukan pada data yang diperoleh pada periode Januari sampai dengan Desember 2006, tanda klinis yang paling sering ditemukan adalah dermatitis sebanyak 63 orang $(31,98 \%){ }^{4}$

Sedikitnya $20 \%$ populasi menunjukan penyakit yang terjadi melalui IgE seperti rhinitis alergi, asma dan dermatitis atopi. Sekitar 50-70\% dari populasi membentuk IgE terhadap antigen yang masuk tubuh melalui mukosa seperti selaput lendir hidung, paru dan konjungtiva. Tetapi hanya 10-20\% masyarakat yang menderita rhinitis alergi dan sekitar 3-10\% yang menderita asma bronchial. ${ }^{14}$

Banyak faktor berperan dalam patogenesis dermatitis yaitu faktor genetik, imunologi, fungsi barier kulit abnormal, dan lingkungan. Salah satu faktor genetik yang menyebabkan dermatitis adalah abnormalitas pada gen yang memproduksi filagrin. Kelainan imunologi pada dermatitis disebabkan ketidakseimbangan antara sel Th1 dan Th2, dimana Th2 lebih dominan. Di Indonesia, prevalensi dermatitis tidak diketahui pasti. Insidensi dermatitis yang terjadi pada 


\section{Research Article}

tahun pertama kehidupan adalah sekitar 85\%, sebanyak 90-95\% kasus muncul sebelum usia 5 tahun. Gangguan sawar kulit pada dermatitis disebabkan gangguan pembentukan seramid pada stratum korneum, yang menyebabkan transepidermal water loss (TEWL) meningkat, sehingga kulit kering dan gatal. Gangguan sawar kulit menyebabkan penetrasi dan absorpsi bahan alergen, iritan dan infeksi lebih mudah. Faktor lingkungan yang berperan dalam patogenesis dermatitis antara lain bahan iritan, alergen hirup (tungau debu rumah, bulu binatang, serbuk sari tumbuhan, spora jamur, alergen makanan, agen infeksi, iklim, stres emosional, dan hormonal. Faktor pencetus eksaserbasi dermatitis umumnya disebabkan paparan lingkungan termasuk bahan iritan dan alergen. ${ }^{5}$

Penelitian di Rumah Sakit Dustira pada tahun 2014 didapatkan TDR sebagai alergen hirup tersering. ${ }^{15}$ Pada RSUD Dr. Soetomo Surabaya Periode 2007-2012 TDR merupakan alergen tersering yang menyebabkan alergi. ${ }^{5}$ Tungau debu rumah (Dermatophagoides pteronyssimus) merupakan salah satu faktor pencetus alergi, dan bagian tubuh tungau yang mengandung alergen adalah kutikula, saluran cerna, dan organ seksual. ${ }^{10}$ Di daerah tropis seperti di Indonesia alergen hirup dalam rumah lebih berpengaruh, sebagian besar disebabkan oleh Dermatophagoides pteronyssimus, Dermatophagoides farinae, dan debu rumah. ${ }^{16}$ Selain tubuh tungau debu rumah (TDR), telah dibuktikan bahwa feses TDR juga mempunyai sifat antigenic. ${ }^{17}$ Alergen yang teridentifikasi pada asma adalah debu rumah, kulit manusia dan TDR, serta kecoa. Alergen rumah banyak ditemui di sekeliling kita misalnya tungau debu rumah yang banyak terdapat pada karpet, atau tempat tidur. ${ }^{18}$

Studi Huss dkk mengukur pajanan alergen dalam rumah dengan risiko asma menyimpulkan bahwa tungau debu rumah (house dust mite) dan kecoa merupakan alergen yang bermakna untuk asma. ${ }^{19}$ Alergen dalam rumah seperti TDR dan kecoa terbukti sebagai faktor risiko asma sedangkan serpihan kulit manusia, kecoa, tungau, bulu anjing, bulu kucing, makanan laut, telur, jamur, dan polen sebagai alergen yang teridentifikasi pada kasus dermatitis atopi. ${ }^{18}$

Pada hasil penelitian didapatkan dari 166 orang dengan 18 jenis bahan uji ( 8 bahan lingkungan dan 10 bahan makanan) didapatkan udang (24,84\%)(Tabel 2) sebagai penyebab alergi makanan tersering. Hal ini berbeda dengan penelitian yang diperoleh sebelumnya mengenai alergi makan yang diperiksa dengan SPT dari 197 orang dengan 21 jenis bahan makanan di Klinik Alergi Rumah Sakit Immanuel periode Januari sampai dengan Maret 2006 didapatkan bahan makanan yang terutama menyebabkan reaksi alergi yaitu kepiting. ${ }^{4}$ Penelitian yang dilakukan oleh Woods et al. diketahui bahwa terdapat $0,53 \%$ orang dewasa yang alergi terhadap udang. ${ }^{20}$ Pada penelitian di Poli Alergi Anak Fakultas Kedokteran Universitas 


\section{Research Article}

Indonesia (FKUI)/ RSCM tahun 2006 diperoleh hasil tes tusuk kulit (skin prick test) terhadap 69 anak dengan asma berusia tiga tahun ke atas yaitu 37,53\% alergi terhadap udang kecil. ${ }^{6}$ Dari data didapatkan 38 Orang $(24,84 \%)$ alergi terhadap udang dan 15 orang $(9,80 \%)$ alergi terhadap kepiting. Hal ini sesuai dengan penelitian di RS Cipto Mangunkusumo dimana alergen makanan terbanyak pada orang dewasa dan anak-anak adalah udang. ${ }^{6}$ Kepiting dan udang temasuk dalam Crustacea yang merupakan hewan laut berkulit keras sedangkan cumi-cumi dan kerang termasuk dalam Molusca golongan hewan laut bertubuh lunak. Crustacea dan Molusca merupakan alergen utama yang mengenai sekitar 250.000 orang dewasa di Amerika. ${ }^{21}$

\section{Simpulan}

Dari penelitian ini didapatkan jumlah pasien alergi yang dilakukan pemeriksaan skin prick test (SPT) di Klinik Alergi Rumah Sakit Immanuel periode Januari 2013 - Desember 2014 berjumlah 206 orang dengan hasil positif 153 orang dan hasil negatif 53 orang. Kelompok usia terbanyak yaitu 31 - 40 tahun, Alergi lebih banyak terjadi pada perempuan dibandingkan dengan laki - laki. Dermatitis merupakan tanda klinis utama. Alergen lingkungan tersering yang menyebabkan alergi adalah tungau debu rumah. Alergen makanan tersering yang menyebabkan alergi adalah udang.

\section{Daftar Pustaka}

1. Tanjung A and Yunihastuti E. Prosedur diagnostik penyakit alergi. Buku ajar ilmu penyakit dalam. Jakarta: Interna Publishing;2009.

2. Garna $\mathrm{KB}$ and Rengganis I. Immunologi dasar, Buku ajar ilmu penyakit dalam. Ed.V. Jakarta: Interna Publishing, 2009.

3. Rengganis I and Yunihastuti E. Alergi makanan. Buku ajar ilmu penyakit dalam. Ed.V. Jakarta : Interna Publishing, 2009.

4. Patricia T. Prevalensi alergi makanan di klinik alergi RS. Immanuel periode Januari 2006 sampai dengan Desember 2006. Bandung. Repository Fakultas Kedokteran Universitas Kristen Maranatha. 2007.

5. Rismauli Fransiska N dan Jusuf B. Penelitian retrospektif uji tusuk kulit pada pasien dermatitis atopik di Unit Rawat Jalan Kesehatan Kulit dan Kelamin RSUD Dr. Soetomo Surabaya Periode 2007-2012. Berkala Ilmu Kesehatan Kulit dan Kelamin, 2015.

6. Candra, Yolanda, Setiarini, Asih and Rengganis, Iris. Gambaran sensitivitas terhadap alergen makanan. Makara Kesehatan. 2011;15(10).

7. Aggrarwal K. Prevalence and risk factors for bronchial asthma in Indian adults: a multicentre study. The Indian J Chest Diseases \& Allied Sci. 2006; 48:13-22

8. World Allergy Organization. White Book on Allergy. s.l. : World Allergy Organization. 2011.

9. Widodo J. Alergi Makanan,Diet dan Autisme. http://gizi.depkes.go.id/. [Online] 2005. [Cited: September 5, 2016.] Available from http://gizi.depkes.go.id/wp-content/uploads/2012/05/alergi-autisme.pdf.

10. Greta MRW dan Janno B, Profil Penderita Alergi dengan Hasil Skin Prick Test TDR Positif di Poliklinik Alergi-Imunologi SMF Ilmu Penyakit Dalam BLU RSUP Prof. DR. R.D. Kandou Manado Periode Januari 2010-Oktober 2012. Journal e-Biomedik. 2013.

11. Harianto DT dan Laode B. Gambaran uji cukit (skin prick test) alergen ingestan pada Mahasiswa Fakultas Kedokteran Universitas Riau Angkatan 2014 yang menderita /menunjukkan Gejala Rinitis Alergi. Jom FK. 2016;1(1)

12. Wistiani dan Notoatmojo S. Hubungan pajanan alergen terhadap kejadian alergi pad anak. Sari pediatric. 2011; 185-90. 


\section{Research Article}

13. Degi PA. Angka Kejadian Alergi Makanan Di Klinik Alergi RS Immanuel Periode April 2012 sampai Dengan

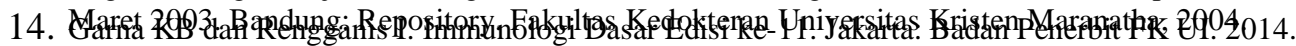

15. Surya Oktaviani P. Identifikasi Alergen Makanan dan Alergen Hirup Penyebab Urtikaria Akut dengan Metode Uji Tusuk Kulit di RS Dustira Cimahi periode Oktober-Desember 2014. Repository Universitas Jendral Achmad Yani. 2015.

16. Sjawitri PPS. Peran Alergi Makanan dan Alergen Hirup pada Peran Alergi Makanan dan Alergen Hirup pada Dermatitis Atopik. Sari Pediatri. 2005; 6(4):155-8.

17. Sungkar. Aspek Biomedis Tungau Debu Rumah. Majalah Kedokteran Indonesia. 2005; 22:23-37.

18. Wistiani dan Notoatmojo H. Hubungan Pajanan Alergen Terhadap Kejadian Alergi pada Anak. Sari Pediatri. 2011;13(3):185-90.

19. Huss RNK, Adkinson JR and Eggleston PA. House dust mite and cockroach exposure are strong risk factors for positive skin test responses in the CAMP. J Allergy Clin Immunol, 2001;107:48-54.

20. Woods RK. Prevalence of Food Allergies in Young Adults and Their Relationship to Asma, Nasal Allergies, and Eczema. Annals Allergy Asma Immunol, 2002:183-9.

21. Rengganis I, Yunihastuti E. Alergi Makanan. Buku Ajar Ilmu Penyakit Dalam. Ed.V. Jakarta: Interna Publishing, 2009. 